\title{
Blockage of glucocorticoid receptors during memory acquisition, retrieval and reconsolidation prevents the expression of morphine- induced conditioned place preferences in mice
}

\author{
Yao-Dong FAN ${ }^{1,5, \#}$, Hai-Chen NIU ${ }^{2, \#}$, Tanzeel Huma ${ }^{2,3}$, Ling LI ${ }^{4}$, Gui-Mei WANG ${ }^{4}$, Li-Qi XU ${ }^{4}$, \\ He REN ${ }^{4}$, Yuan-Ye MA ${ }^{2, *}$, Hua-Lin YU ${ }^{5, *}$ \\ 1. Department of Neurosurgery, The Third Affiliated Hospital of Kunming Medical University (Yunnan Province Tumor Hospital), Kunming 650118, China \\ 2. Kunming Institute of Zoology, Chinese Academy of Sciences, Kunming 650223, China \\ 3. Laboratory of Reproductive Neuroendocrinology, Department of Animal Sciences, Faculty of Biological Sciences, Quaid-i-Azam University, Islamabad \\ 45320, Pakistan \\ 4. Kunming General Hospital of Chengdu Military Region, People's Liberation Army, Kunming 650032, China \\ 5. Minimally Invasive Neurosurgery Department, The First Affiliated Hospital of Kunming Medical University, Kunming 650032, China
}

\begin{abstract}
Association between the reward caused by consuming drugs and the context in which they are consumed is essential in the formation of morphine-induced conditioned place preference (CPP). Glucocorticoid receptor (GRs) activation in different regions of the brain affects reward-based reinforcement and memory processing. A wide array of studies have demonstrated that blockage of GRs in some brain areas can have an effect on reward-related memory; however, to date there have been no systematic studies about the involvement of glucocorticoids (GCs) in morphine-related reward memory. Here, we used the GR antagonist RU38486 to investigate how GRs blockage affects the sensitization and CPP behavior during different phases of reward memory included acquisition, retrieval and reconsolidation. Interestingly, our results showed RU38486 has the ability to impair the acquisition, retrieval and reconsolidation of reward-based memory in CPP and sensitization behavior. But RU38486 by itself cannot induce CPP or conditioned place aversion (CPA) behavior. Our data provide a much more complete picture of the potential effects that glucocorticoids have on the reward memory of different phases and inhibit the sensitization behavior.
\end{abstract}

Keywords: Addiction; Conditioned place preference; RU38486; Glucocorticoid receptor; Retrieval; Reconsolidation; Reward memory

Opiate addiction is a chronic brain disorder characterized by compulsive drug seeking and accompanied by a high risk of relapse, even after long periods of abstinence, which is often precipitated by drug-associated cues (De Vries \& Shippenberg, 2002). These environmental cues are paired with the reward from opiate exposure and together shape addictive memory ( Valjent et al, 2006). At present, numerous studies indicate that opiate exposure can pathologically usurp neural mechanisms of learning and memory, even under normal circumstances (Hyman et al, 2006).

Conditioned place preference (CPP) has commonly been applied to study the effects of various drugs on reward-related memory (Bardo \& Bevins, 2000). In this procedure, drugs are repeatedly administered paired with a particular environment. When subjects have obtained addictive memory, the drug-paired environments elicit drug-seeking behavior in a drug free drug state (Bardo \& Bevins, 2000). If the animal stays longer in drug-paired environments than in non drug-paired environments, that drug-paired environments could be said to have acquired a conditioned incentive property. In CPP training, the reward-related memories consist of acquisition, retrieval and reconsolidation phases. During acquisition, animals receive the drug or saline in an appropriate, distinctive

Received: 06 June 2012; Accepted: 30 October 2012

\#The authors contributed equally in this study

* Corresponding author, E-mail: yuanma0716@vip.sina.com; yuhl308@126.com 
chamber and then form memories about the drug and cues. In the retrieval phase, cues previously associated with the receipt of drugs strongly induce animals to reinstate drug-seeking and drug-taking behavior ( Lai et al, 2008). Afterward, the reconsolidation phase that follows memory retrieval begins once a previously consolidated memory is activated by conditioned cues, causing memory to enter a labile state that is vulnerable to disruption (Nade, 2003).

Glucocorticoid receptors (GRs) are highly expressed in the olfactory tubercle, nucleus accumbens, striatum, amygdala, hippocampus, hypothalamus and, to a larger extent, areas of the cerebral cortex ( Pesini et al, 1998). Glucocorticoid (GC) hormone can mediate a variety of nervous functions including pain, mood, reward, cognition and affect ( Wolkowitz et al, 2009). A previous study found that the administration of corticosterone was able to precipitate the reinstatement of cocaine self-administration (Deroche et al, 1997). Adrenalectomy significantly blocked the potentiation of CPP to morphine induced by previous inescapable shock ( Der-Avakian et al, 2005). Intermittent exposure to foot shocks delayed the extinction of CPP (Wang et al, 2006), and reinstated morphine CPP after extinction (Wang et al, 2006). Some studies, however, reported that blockage of GR using RU38486 in the hippocampus and nucleus accumbens (NAc) impaired the formation of morphine CPP in Sprague-Dawley rats (Dong et al, 2006). But, GRs blockage's effects on memory and motivation have not reported.

To systemically examine precisely how GR blockage affects reward memory and motivation behavior, we used the GR antagonist (RU38486) and the CPP/ sensitization model in mice and examined if blockage of GRs could pharmacologically affect the acquisition (Experiment 1), retrieval (Experiment 2) and reconsolidation (Experiment 3) of reward-related memory in CPP. Furthermore, we also tested whether RU38486 can affect sensitization behaviors (Experiment 5).

\section{METHODS AND MATERIALS}

\section{Animals}

Male ICR mice (Animal Center, Kunming Medical College, weighing 20-25 g, 8 weeks of age) were housed in plastic cages with free access to food and water (8 mice/cage) at room temperature $\left[(25 \pm 1){ }^{\circ} \mathrm{C}\right.$ under a $12 \mathrm{~h}$ light/dark cycle (white lights on: 08:00-20:00)]. All animals were treated in accordance with the guidelines of the National Institutes of Health on principles of animal care. Animal facilities and experimental protocols adhered to the guidelines of the Association for Assessment and Accreditation of Laboratory Animal Care. Each of the following experiments used an independent set of animals.

\section{Drugs}

RU38486 (Zhejiang Xianju Pharmaceuticals Company) or its vehicle ( $0.9 \%$ saline) were given as a single dose via intraperitoneal (i.p.) injection. Morphine hydrochloride was purchased from the First Manufactory of Shen Yang, China.

\section{Apparatus and behavioral experiments}

CPP Apparatus:Tests were conducted in identical rectangular enclosures of equally sized wooden boxes with compartments $(30.7 \mathrm{~cm}$ length $\times 31.5 \mathrm{~cm}$ width $\times 34.5$ $\mathrm{cm}$ height) separated by a gray start compartment $(13.8$ $\mathrm{cm}$ length $\times 10.5 \mathrm{~cm}$ width $\times 34.5 \mathrm{~cm}$ height) with two removable, black guillotine doors. The two compartments had different visual features (horizontal or vertical black and white stripes, placed at equal intervals) and distinct floor textures (smooth in the horizontally striped compartment and rough in the vertical stripes compartment) (Tilley et al, 2007). A video camera was suspended from the ceiling to record the location of each mouse. The time spent in each compartment was manually analyzed offline.

\section{CPP Behavioral procedure:}

The experiment included a pretest, conditioning, and test phase. All subjects were weighed and briefly handled daily prior to the CPP procedures and all CPP studies were conducted during the same time of day.

From days 1-3, mice were preconditioned for the morphine place preference procedure as follows. Animals were placed in the central compartment with both doors open to freely explore the apparatus for 15 min per day. All compartments were cleaned and wiped dry between animal runs. After three days of preconditioning, mice were determined for initial preference on day 3. Animals showing a strong unconditioned aversion (less than $30 \%$ of session time) or preference (more than $70 \%$ of session time) for any compartment were discarded (11 mice were discarded in total) (Carey et al, 2005). From days 4-7, mice were conditions by the administration of morphine to the nonpreferred side and saline on preferred side. Mice were treated for eight consecutive sessions with alternating injections of morphine $(40 \mathrm{mg} / \mathrm{kg}$, i.p.) or saline $(1 \mathrm{~mL} / \mathrm{kg}$, i.p.) during the training period (Tan et al, 2007). The injection time order (morning or afternoon) was counterbalanced with 6 hours intervals between morphine and saline (Song et al, 2007; Do Couto et al 2003). Thus, every animal received both a morphine and saline injection each day.

The test day for morphine-induced CPP was done $24 \mathrm{~h}$ after the last conditioning day. Each animal was placed into the central compartment and had free access to all compartments in the $15 \mathrm{~min}$ test period. During the test, the animals' time spent in each compartments was 
recorded, including expression, extinction and reinstatement. Expression: The CPP expression test took place $24 \mathrm{~h}$ after the last conditioning day. Mice were placed in the center compartment in a drug-free state and allowed to explore the entire chamber for $15 \mathrm{~min}$ while we recorded the time spent in each compartment. Extinction: After CPP expression, mice were not given extinction test once a day until CPP extinction. No injections were given during the extinction period (Bahi et al, 2008; Bilbao et al, 2008; Mueller \& Stewart, 2000). If the time spent in the drug paired side was not significantly different from the time spent in the no drug paired side, CPP were deemed extinguished. Reinstatement: All mice were tested for the reinstatement of CPP immediately after receiving a priming injection of morphine $(2.0 \mathrm{mg} / \mathrm{kg}$, i.p.) or saline $(0.1 \mathrm{~mL} / \mathrm{kg}$, i.p.)The day following the last extinction trial,. During this reinstatement test, animals were allowed to freely access to the entire apparatus for $15 \mathrm{~min}$, and the time spent in each chamber was measured.

Locomotion activity: Locomotive activity in wooden cages $(0.35 \mathrm{~m} \times 0.35 \mathrm{~m} \times 0.3 \mathrm{~m})$ was recorded by automatic tracking system with computer-monitored infrared detector.

\section{Experimental Design}

\section{Experiment 1: Effects of RU38486 on acquisition of} morphine CPP

Experiment 1 was performed to examine the effects of RU38486 on the acquisition of morphine rewardrelated memory. Morphine CPP conditioning was identical to that in the previous experiments ( Tan et al, 2007). After preconditioning, either different doses of RU38486 (10, 20, and $30 \mathrm{mg} / \mathrm{kg}$, i.p.) or vehicle were administrated $15 \mathrm{~min}$ prior to morphine or vehicle. On day 8 , all groups received a drug-free preference test at $15 \mathrm{~min}$. The experimental design for experiment 1 is illustrated in Figure 1A.

\section{Experiment 2: Effect of RU38486 on retrieval of morphine CPP}

Experiment 2 was designed to determine whether the ability of RU38486 disrupted the retrieval of morphine CPP. After CPP training as described above, animals were tested for CPP expression on day 8 (postconditioning). Then, retrieval of reward memory was tested on days 9, 12, 15, and 18. Mice were administrated RU38486 (10, 20, and $30 \mathrm{mg} / \mathrm{kg}$, i.p.) or vehicle $15 \mathrm{~min}$ prior to every retrieval tests. The experimental design for experiment 2 is illustrated in Figure 2A.

\section{Experiment 3: Effect of RU38486 on reconsolidation of morphine CPP}

Experiment 3 was conducted to determine the
A
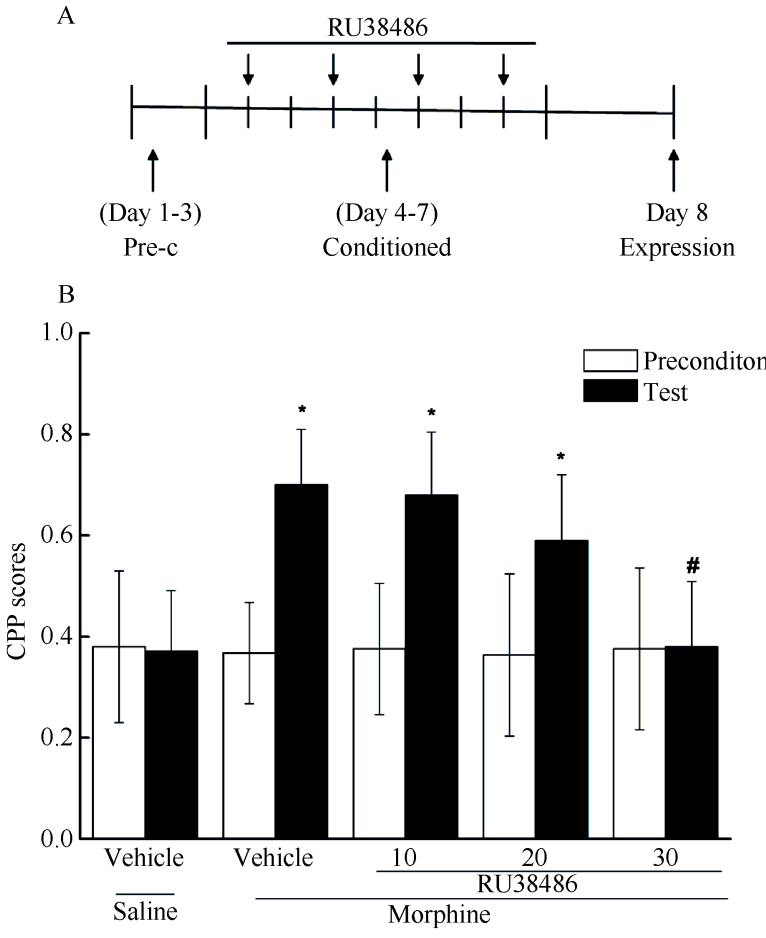

Figure 1 Effects of RU38486 on the acquisition of morphine reward-related memory

A: Behavioral procedure; B: RU38486 disrupted the acquisition of morphine reward memory.

A significant difference was found for post-conditioning CPP scores contrasted with precondition scores in morphine group (morphine-vehicle), 10 RU38486 group (morphine-10 $\mathrm{mg} / \mathrm{kg}$ RU38486, $P<0.05$ ), and 20 RU38486 group (morphine-20mg/kg RU38486, $P<0.05$ ). However, no significant difference was found for post-conditioning CPP scores contrasted with precondition scores in 30 RU38486(morphine-30 mg/kg RU38486) group $(P>0.05)$. *: a significant difference contrasted with precondition score $(P<0.05)$; \#: a significant difference contrasted with morphine (morphine-vehicle) group $(P<0.05)$; Data $(n=8)$ are expressed as mean $\pm S E M$.

effects of RU38486 on the reconsolidation of morphine reward memory. Mice were trained for morphineinduced CPP and reconsolidation of reward memory was done in drug-paired compartment for 45 minutes (Milekic et al, 2006). Immediately after the reconsolidation session, different doses of UR38486 or vehicle were injected to investigate the effects on memory reconsolidation. Mice received one of the following treatments: vehicle, RU38486 (10 mg/kg, i.p.), RU38486 (20 mg/kg, i.p.) and RU38486 (30 mg/kg, i.p.). After $24 \mathrm{~h}$, reconsolidation of reward memory in $15 \mathrm{~min}$ was test for each group. The experimental design for experiment 3 is illustrated in Figure 3A.

Experiment 4: Rewarding or aversive effects of the RU38486 per se in mice

To rule out the possibility that RU38486 has a rewarding or aversive effect, in experiment 4 we tested whether CPP or CPA behavior could be induced by 


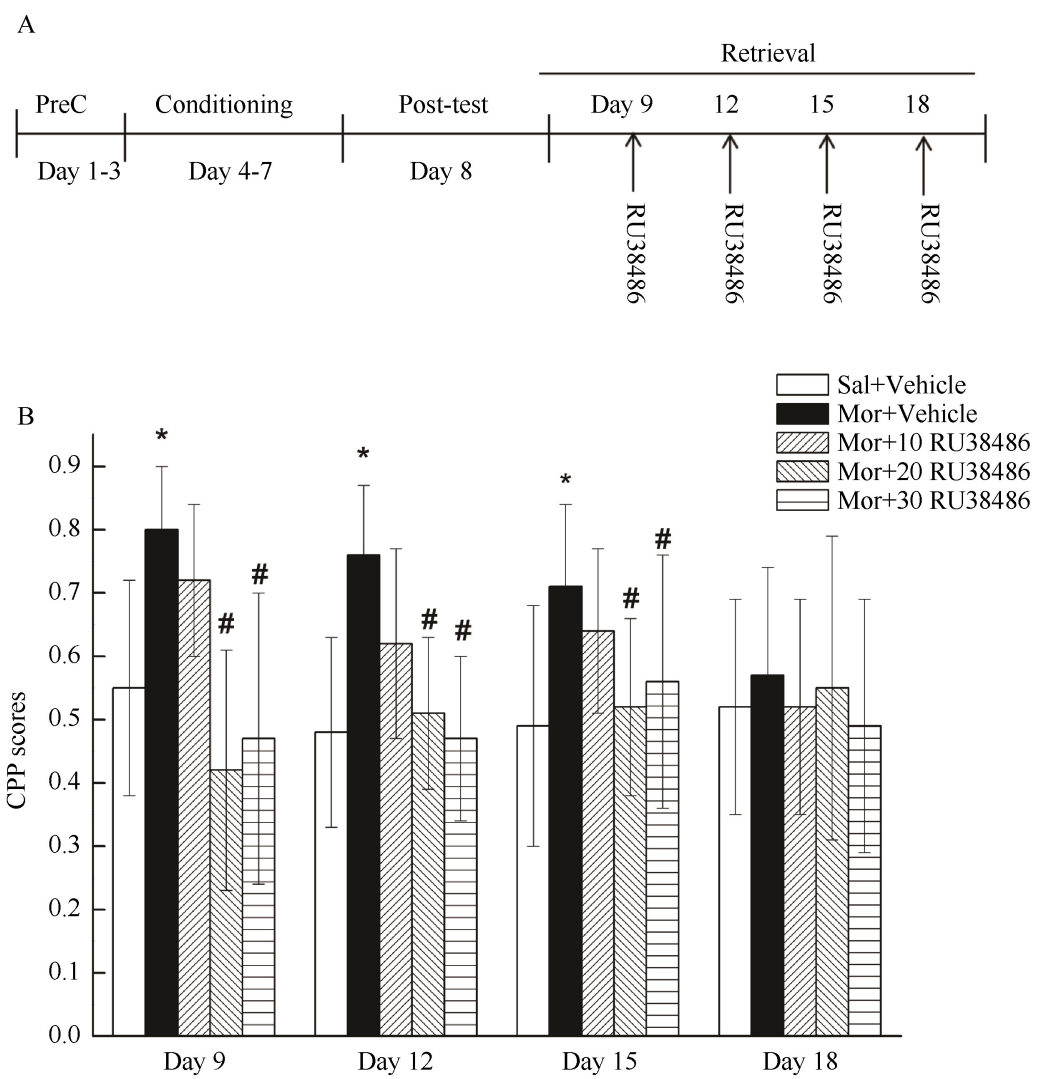

Figure 2 Effect of RU38486 on the retrieval of morphine reward-related memory

A: Behavioral procedure; B: RU38486 disrupted the retrieval of morphine reward memory. *: the vehicle-treated animals that received morphine were significantly different than the control group $(P<0.05)$; \#: the groups treated with RU38486 were significantly different than the morphine group (vehicle-treated animals that received morphine, $P<0.05)$; Data $(n=8)$ are expressed as mean $\pm S E M$.

A
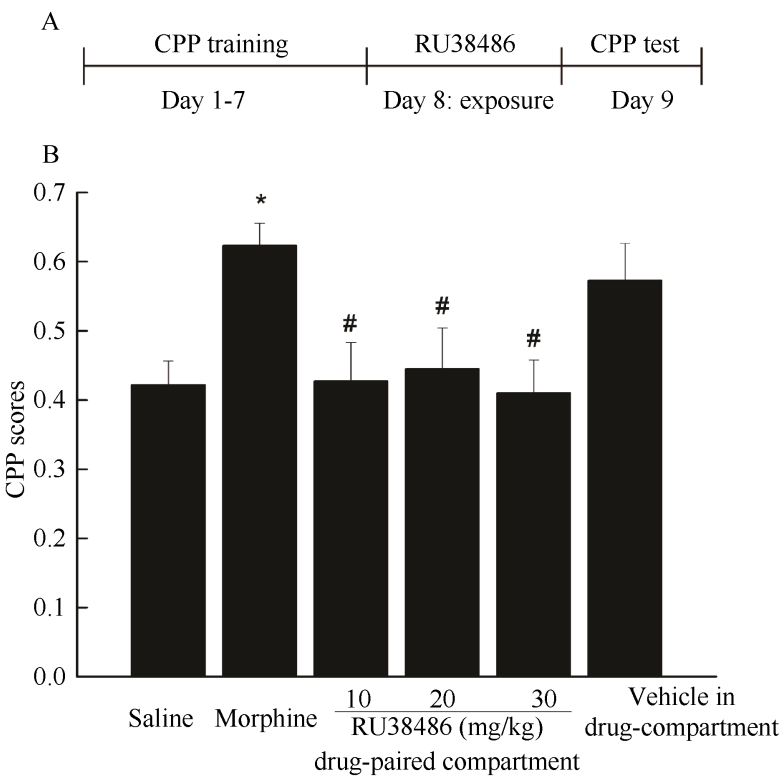

Figure 3 Effects of RU38486 on the reconsolidation of morphine reward-related memory

A: Behavioral procedure; B: RU38486 disrupted the reconsolidation of morphine reward memory. A significant difference was found $24 \mathrm{~h}$ after reconsolidation between the vehicle group and RU38486 treatment $(10,20$ and $30 \mathrm{mg} / \mathrm{kg}$ ); *: $P<0.05$ compared with morphine group (vehicle-treated animals that received morphine); Data $(n=8)$ is expressed as mean $\pm S E M$.

Kunming Institute of Zoology (CAS), China Zoological Society
RU38486 alone. Mice were randomly divided into four groups, of 16-20 mice in each group: the vehicle group, 10RU38486 (10 mg/kg) group, 20RU38486 (20 mg/kg) group and 30RU38486 (30 mg/kg) group. After the preconditioning phase, every group was further divided into two equally sized groups. For half of the mice, the smooth compartment was paired with different doses of RU38486, and the rough compartment was paired with saline $(0.1 \mathrm{~mL} / \mathrm{animal})$. For the other half of the mice, the rough compartment was paired with the above doses of RU38486 and the smooth compartment with saline. The training lasted for three days. During the testing (day $8)$, the time spent in the two compartments was recorded.

\section{Experiment 5: Effects of RU38486 on the morphine- induced sensitization}

To determine the effects of RU38486 on the development of morphine-induced sensitization, the mice were pretreated in open-field cages for five consecutive days. Before pretreatment sessions, the mice were first allowed to habituate to the open field for $30 \mathrm{~min}$ in three consecutive days and were then divided into control group (saline-vehicle), morphine group (morphinevehicle), 10 RU38486 group (morphine-10 mg/kg RU38486), 20 RU38486 group (morphine-20 mg/kg 
RU38486) and 30 RU38486 group (morphine-30 mg/kg RU38486). At $15 \mathrm{~min}$ after the administration of RU38486 or vehicle, the mice were injected with either morphine (40 $\mathrm{mg} / \mathrm{kg}$, i.p.) or saline to sensitization conditioning. The pretreatment dose of morphine used was based on pilot studies. At 30 days after the last pretreatment session, the mice were challenged with morphine $(5 \mathrm{mg} / \mathrm{kg}$ ) (Cordonnier et al, 2007). The locomotor activity of animal was tested after $30 \mathrm{~min}$.

\section{Statistical analysis}

During the CPP testing phase, the amount of time spent by the mice in the chambers was recorded by a computer, and preference scores determined by the time spent in the drug-paired compartment divided by the total time in both compartments. To determine whether trained mice exhibited a significant conditioned place preference or aversion, preference scores were contrasted using repeated measures ANOVA with the day-factor as the within-groups variable and group-factor as the between-groups variable. This analysis was followed by between-group comparisons, which were completed with a post hoc analysis (LSD) test in SPSS 13.0 (Gerdjikov \& Beninger, 2006). All behavioral data were collected from videorecordings was obtained by an investigator blind to the experimental conditions that performed offline manual scoring.

\section{RESULTS}

\section{Effect of RU38486 on the acquisition of morphine reward memory}

In order to determine the involvement of GRs activity in acquisition of morphine CPP, RU38486 or vehicle was administered the 15 min prior to morphine or saline exposures during each conditioned trial. Repeated measures ANOVA revealed that a significant main effect $\left(\mathrm{F}_{(4,31)}=6.089, P=0.001\right)$ was found after conditioned training contrasted with preference score of precondition (Figure 1B). Post hoc analysis (LSD) then showed that the morphine group as compared with the control group spent more time in the drug-paired compartment $(P=0.003)$. Oppositely, the RU38486-treated animals (10, 20 and $30 \mathrm{mg} / \mathrm{kg}$ ) that received morphine showed a significant attenuated preference effects $(P=0.003$, $P=0.003, \quad P=0.0005$, respectively) contrasted with vehicle-treated animals. These data showed that RU38486 was able to impair either morphine reward or the memory formation necessary for acquisition of morphine CPP in mice.

\section{Effect of RU38486 on retrieval of morphine reward memory}

In order to determine the involvement of GRs activity in retrieval of morphine CPP, RU38486 or vehicle was administered the $15 \mathrm{~min}$ prior to retrieval test. As shown in Figure $2 \mathrm{~B}$ the repeated measure ANOVA (two-way) was conducted on CPP score using doses of RU38486 (10, 20 and $30 \mathrm{mg} / \mathrm{kg})$ as the between-subjects factors and test (day 9, day 12, day 15 and day 18) as the within-subjects factor revealed a significant effect of dose $\left[F_{(3,34)}=3.853, P<0.05\right]$. There was also a significant interaction of group $\times$ day $\left[F_{(12,34)}=2.363, P<0.05\right]$. Pre-test injection of RU38486 treatment markedly blocked the expression of morphineinduced CPP in mice $(20 \mathrm{mg} / \mathrm{kg}$ RU38486 group vs. morphine group: $P=0.016 ; 30 \mathrm{mg} / \mathrm{kg}$ RU38486 group vs. morphine group: $P=0.026$ ). The results of pair-wise comparisons for each day showed that there were still significant differences for the CPP score in the morphine as compare with saline on day 9 , day 12 and day 15 test. There was no significant difference on the test conducted on day 18. In apparel, post-hoc tests (LSD) showed that the morphine group had significantly increased scores $(P=0.008)$ as compared with the control group. In general, the above results indicated that blockage of GR substantially attenuates the retrieval of morphine-induced CPP.

\section{Effect of RU38486 on the reconsolidation of morphine reward-related memory}

In order to determine the involvement of GRs activity in reconsolidation of morphine CPP, RU38486 or vehicle was administered immediately after memory activity. One-way ANOVA showed a significant difference between groups $\left(F_{(5,48)}=2.580, P=0.021\right)$ and post-hoc analysis revealed that, after morphine training, morphine group mice acquired CPP (morphine vs. saline: $P=0.005$ ) (Figure 3B). RU38486-treated groups placed in the drug-paired compartment showed significant inhibitory effects on the expression of CPP (morphine vs. $10 \mathrm{mg} / \mathrm{kg}$ RU38486: $P=0.006$; morphine vs. $20 \mathrm{mg} / \mathrm{kg}$ RU38486: $P=0.013$; morphine vs. $30 \mathrm{mg} / \mathrm{kg}$ RU38486: $P=0.006$ ). However, animals treated with vehicle in drug-paired compartment did not show a significant inhibitory effect on the expression of CPP (morphine vs. morphine vs. vehicle: $P=0.312$ ). Together, these results demonstrate the inhibitory effect of RU38486 on reconsolidation of morphine reward-related memory within $24 \mathrm{~h}$ and emphasize the importance of rewardrelated cues.

\section{Rewarding or aversive effects of the RU38486 per se in mice}

In order to determine the effect of RU38486 on the rewarding or aversive effects in mice. The effects of i.p. administration of RU38486 (10, 20, $30 \mathrm{mg} / \mathrm{kg})$ on the expression of place preference are shown in Figure 4. In this protocol, whether RU38486 can induce CPP or CPA was tested in the CPP procedure. RU38486 was paired 
with the smooth or rough compartment, and the training lasted for 3 days like the morphine CPP procedure. Group scores were compared, and the results showed no differences between the rough $\left(F_{(3,28)}=0.230, P=0.875\right)$ and smooth $\left(F_{(3.28)}=0.251, P=0.752\right)$ groups. These data further indicate that RU38486 cannot induce CPP or CPA behavior in mice at these doses, and that RU38486 has no direct effects on either reward or aversion.

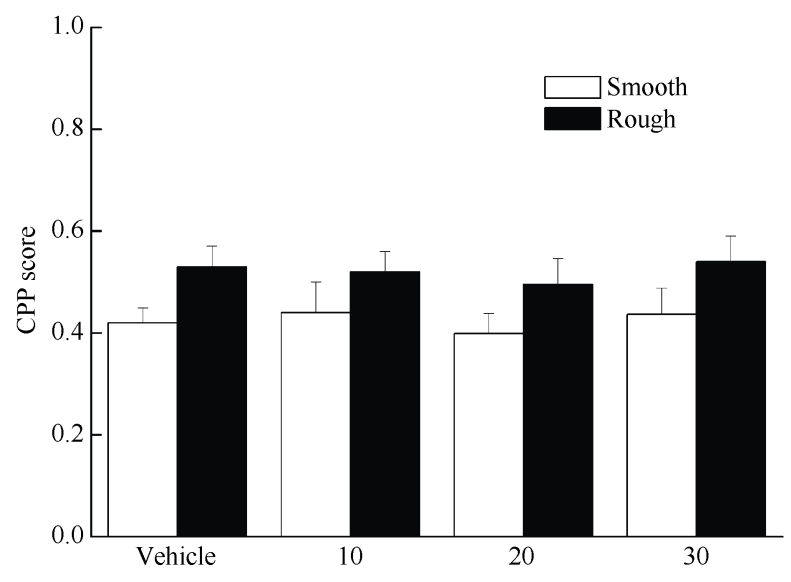

Figure 4 RU38486-induced expression of CPP in mice The effects of RU38486 alone were tested on the expression of conditioned place preference in mice. Results showed that these three doses of RU38486 do not induce the expression of CPP in mice, independent of whether mice were conditioned in the rough or smooth compartment. Time spent was not different in the smooth or rough compartment per dose. Bars $(n=8)$ show mean $\pm S E M$

\section{Effect of RU38486 on the sensitization in mice}

Morphine-induced sensitization during the challenge session is altered by RU38486 pretreatment (Figure 5). One-way ANOVA showed a significant difference between groups $\left(\mathrm{F}_{(4,35)}=6.783, P<0.05\right)$ and post-hoc analysis revealed that, after morphine challenged (5 $\mathrm{mg} / \mathrm{kg}$ ), RU38486 inhibited the sensitization behavior (vehicle-morphine vs. 10 RU38486, $P<0.05$; vehiclemorphine vs. 20 RU38486, $P<0.003$; vehicle-morphine vs. 30 RU38486, $P<0.05)$. These data showed that RU38486 was able to impair morphine induced sensitization.

\section{DISCUSSION}

Our study illustrates that drug associated learning and memory played a key role in drug craving and psychological dependence. The conditioned place preference paradigm has been extensively used in drug addiction research to investigate reward-related learning and memory (Bardo \& Bevins, 2000). Here, during conditioning, animals are trained in one environment paired with drugs and another paired with saline. On the test day, animals were freely given access to both environments in a drug-free state and their preferences

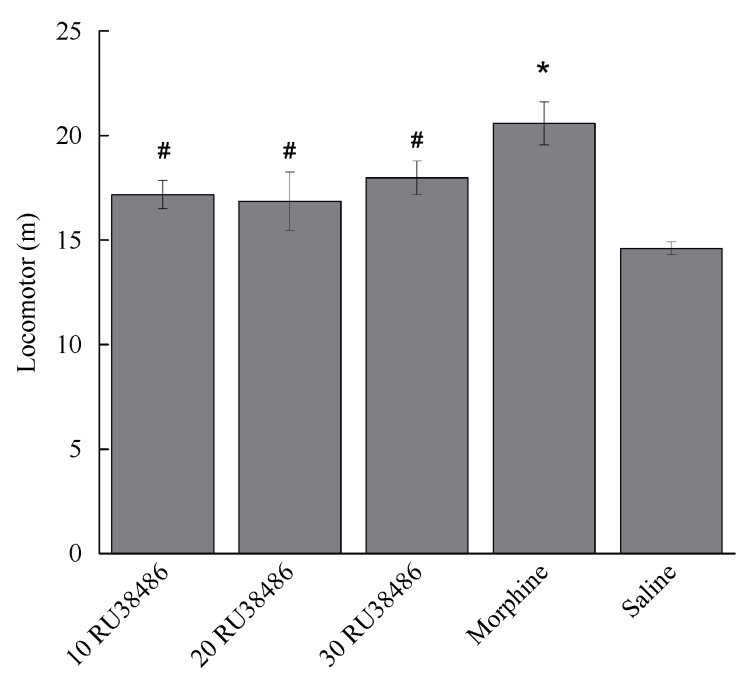

Figure 5 Effect of RU38486 on the sensitization in mice *: $P<0.05$ compared with control group; \#: $P<0.05$ compared with morphine. Bars $(n=8)$ show mean $\pm S E M$.

for drug- versus saline-paired environments are assessed, the expression test is thought to be a measure of memory acquisition, retrieval and reconsolidation (Han et al, 2010; Zhai et al, 2008). The current study was designed to examine the role of GRs receptor antagonist, RU38486, in morphine-related reward memory, using the CPP paradigm. Current results show that a) treatment with RU38486 attenuated the expression of reward-related memory in the CPP paradigm included the acquisition, retrieval and reconsolidation; b) RU38486 itself did not induce a conditioned placed preference or aversion; c) RU38486 disturbed the sensitization behaviors of mice. Our results demonstrate that morphine-induced reward memory included the acquisition, retrieval and reconsolidation in CPP model and sensitization behaviors that involve GRs can be destroyed by RU38486.

Based on previous studies, there are three important factors in the CPP procedure. First, the drug has rewarding properties that establish the drug-seeking motivation that drives the animals to establish a place preference (Meng et al, 2009). Second, animals can remember the drug-associated cues, which reactivate the reward-related memories. Both environmental contexts and specific environmental cues associated with a drug consistently seem to be able to reinstate drug-seeking behaviors in abstinent subjects (Shalev et al, 2002). Finally, the associative memories formed in CPP procedures are both stable and persistent. Therefore, treatments attenuating the expression of CPP may act by disrupting any of these three factors.

Piazza \& Le Moal (1997) administered drugs, such as opiates and psychostimulants, which could elevate the level of glucocorticoids and DA in NAc and enhance the reward and memory procedure in the CPP model. During 
the acquisition of reward memory, blockage of GRs could attenuate the DA response to drug which impaired the conditioned learning. Firstly, DA responses to drugs may be mediated in part by glucocorticoids, as surgical or pharmacological adrenalectomy (without basal replacement) attenuated self-administration and locomotor responses to cocaine as well as the DA response in NAc to morphine (Barrot et al, 2000; Goeders \& Guerin, 1996). Previous studies showed that corticosterone-induced dopamine release was further increased (ca. 80\% above the baseline) if the hormone was administered in parallel with reward-related activities (Piazza et al, 1996). Treatment with RU38486 during acquisition led to the impaired reward. On the other side, learned association between drugs abuse and context is essential for the formation of drug conditioned place preference (CPP) and glucocorticoid hormones also play an important role in this action. Blockage of GRs can disturb the conditioning learning by RU38486, leading to the impairment of reward memory acquisition. Animal and human studies have also indicated that the administration of low doses of glucocorticoid hormones enhanced memory for stressful or emotionally arousing events (Roozendaal et al, 2009). These enhancing effects depend on the integrity of the amygdala noradrenergic system (Roozendaal et al, 2009). In general, acquisition of reward memory in CPP was perhaps was destroyed by the two ways.

Neural circuits of associative learning include several brain regions, such as the hippocampus, and basolateral amygdala, medial prefrontal cortex, orbitofrontal cortices (Dong et al, 2006; Maratos et al, 2001), and GRs are widely distributed in these areas(Piazza \& Le Moal, 1997). Riedel et al (1999) addressed the role of the hippocampus in retrieval by training animals to form a spatial preference with normal hippocampal function. When the hippocampus was temporarily inactivated before a spatial memory test, retrieval was impaired (Riedel et al, 1999). Similarly, glucocorticoid effects on memory retrieval were recently reported in human subjects. Oral administration of stress doses of cortisone $1 \mathrm{~h}$ before retention testing impaired hippocampal-dependent free recall of previously learned words (de Quervain et al, 2000). These findings demonstrated that once memories are consolidated, the efficacy or accuracy of the information retrieved remains vulnerable to glucocorticoids at the time of recall. Here, the administration of RU38486 15 min given prior to the reward-memory retrieval that served as reactivation sessions and resulted in a significant suppression in morphine-induced CPP in the following test. However, within the brain the mechanism of change in the gene transcriptions and expressions involved by RU38486 are not clear.
Reconsolidation is the process by which previously consolidated memories are stabilized after retrieval. Disruption of reward-related memories in a reactivationdependent manner is thought to be due to the disruption of memory reconsolidation processes (Zhao et al, 2011). A recent study showed immediately following memory reactivation, intrahippocampal or systemic administration of the GRs antagonist RU38486 in rats that were trained and tested in an inhibitory avoidance task showed a deficit in reconsolidation memory (Nikzad et al, 2011). Other studies found that a matrix metalloproteinase inhibitor (Brown et al, 2009), a $\beta$ noradrenergic receptor antagonist (Debiec \& Ledoux, 2004) or N-methyl-D-aspartate (NMDA) receptor antagonists (Brown et al, 2008) can also interfere with the reconsolidation of drug-associated CPP memories. These studies showed that disrupting the reconsolidation process of drug-associated memory formation may be a potential target useful in treating drug addiction (Lee et al, 2005; Nader et al, 2000). In the reconsolidation test, systematic administration of RU38486 could impair the reconsolidation of morphine reward memory. On the contrary, Wang et al (2008) reported that the disruptive effect of stress on reconsolidation of morphine related memory was prevented by inhibition of corticosterone synthesis with metyrapone or injections of the glucocorticoid antagonist RU38486 in BLA. The difference between their results and ours may be due to different treatment methodology, different involved brain regions or a different level of glucocorticoid hormones in reconsolidation. Thus, our findings imply that the RU38486 may impair the reconsolidation of reward memory through inactivation of GRs in the whole brain, which may include in the hippocampus as well.

Our study also shows that expression of the GR is a necessary condition for the development of morphineinduced sensitization at the behavioral levels. This finding is important for two reasons. First, sensitization to the effects of a drug is considered a major process in the development of drug abuse, because it should mediate the uncontrollable motivation for the drug that characterizes addiction (Robinson \& Berridge, 1993). Second, the results show that the GCs are included in neuroadaptive process. Notably, our previous data indicated that the GRs seemed to be involved in mediating not the basal behavioral effects of morphine, but, selectively, the excessive response to the drug. Similarly, previous report showed that RU38486 (mifepristone) did not block the acute response to cocaine but selectively suppressed cocaine-induced sensitization (De Vries et al, 1996). Our experiments, by using a pharmacological invalidation approach, demonstrate that the GRs are strongly implicated in the development of sensitization. 
In conclusion, using the CPP procedure, we found that morphine can induce CPP in mice, whereas RU38486 alone cannot induce CPP or CPA. Treatment with RU38486 prior to morphine conditioning can

\section{References}

Bahi A, Kusnecov A, Dreyer JL. 2008. The role of tissue-type plasminogen activator system in amphetamine-induced conditional place preference extinction and reinstatement. Neuropsychopharmacology, 33(11): 2726-2734.

Bardo MT, Bevins RA. 2000. Conditioned place preference: what does it add to our preclinical understanding of drug reward? Psychopharmacology, 153: 31-43.

Barrot M, Marinelli M, Abrous DN, Rouge-Pont F, Le Moal M, Piazza PV. 2000. The dopaminergic hyper-responsiveness of the shell of the nucleus accumbens is hormone-dependent. Eur J Neurosci, 12(3): 973979.

Bilbao A, Parkitna JR, Engblom D, Perreau-Lenz S, Sanchis-Segura C, Schneider M, Konopka W, Westphal M, Breen G, Desrivieres S, Klugmann M, Guindalini C, Vallada H, Laranjeira R, de Fonseca FR, Schumann G, Schutz G, Spanagel R. 2008. Loss of the $\mathrm{Ca}^{2+} /$ calmodulin-dependent protein kinase type IV in dopaminoceptive neurons enhances behavioral effects of cocaine. Proc Natl Acad Sci USA, 105(45): 17549-17554.

Brown TE, Lee BR, Sorg BA. 2008. The NMDA antagonist MK-801 disrupts reconsolidation of a cocaine-associated memory for conditioned place preference but not for self-administration in rats. Learn Mem, 15(12): 857-865.

Brown TE, Wilson AR, Cocking DL, Sorg BA. 2009. Inhibition of matrix metalloproteinase activity disrupts reconsolidation but not consolidation of a fear memory. Neurobiol Learn Mem, 91(1): 66-72.

Carey RJ, DePalma G, Damianopoulos E. 2005. Evidence for pavlovian conditioning of cocaine-induced responses linked to emotional behavioral effects. Pharmacol Biochem Behav, 80(1): 123-134.

Cordonnier L, Sanchez M, Roques BP, Noble F. 2007. Blockade of morphine-induced behavioral sensitization by a combination of amisulpride and RB101, comparison with classical opioid maintenance treatments. Br J Pharmacol, 151(1): 94-102.

Debiec J, Ledoux JE. 2004. Disruption of reconsolidation but not consolidation of auditory fear conditioning by noradrenergic blockade in the amygdala. Neuroscience, 129(2): 267-272.

De Vries TJ, Schoffelmeer AN, Tjon GH, Nestby P, Mulder AH, Vanderschuren LJ. 1996. Mifepristone prevents the expression of longterm behavioural sensitization to amphetamine. Eur J Pharmacol, 307(2): R3-R4.

De Vries TJ, Shippenberg TS. 2002. Neural systems underlying opiate addiction $J$ Neurosci, 22(9): 3321-3325.

Der-Avakian A, Will MJ, Bland ST, Deak T, Nguyen KT, Schmid MJ, Spencer RL, Watkins LR, Maier SF. 2005. Surgical and pharmacological suppression of glucocorticoids prevents the enhancement of morphine conditioned place preference by uncontrollable stress in rats. Psychopharmacology, 179(2): 409-417. attenuate the acquisition, retrieval and reconsolidation of reward memory. Simultaneously, RU38486 also blocked the sensitization behaviors; these results suggest that GRs may play an important role in addiction procedure.

de Quervain DJ, Roozendaal B, Nitsch RM, McGaugh JL, Hock C. 2000. Acute cortisone administration impairs retrieval of long-term declarative memory in humans. Nat Neurosci, 3(4): 313-314.

Deroche V, Marinelli M, Le Moal M, Piazza PV. 1997. Glucocorticoids and behavioral effects of psychostimulants. II: cocaine intravenous selfadministration and reinstatement depend on glucocorticoid levels. $J$ Pharmacol Exp Ther, 281(3): 1401-1407.

Do Couto BR, Aguilar MA, Manzanedo C, Rodriguez-Arias M, Minarro J. 2003. Reinstatement of morphine-induced conditioned place preference in mice by priming injections. Neural Plast, 10(4): 279-290.

Dong Z, Han H, Wang M, Xu L, Hao W, Cao J. 2006. Morphine conditioned place preference depends on glucocorticoid receptors in both hippocampus and nucleus accumbens. Hippocampus, 16(10): 809813.

Gerdjikov TV, Beninger RJ. 2006. Place preference induced by nucleus accumbens amphetamine is impaired by local blockade of Group II metabotropic glutamate receptors in rats. BMC Neurosci, 7: 43.

Goeders NE, Guerin GF. 1996. Effects of surgical and pharmacological adrenalectomy on the initiation and maintenance of intravenous cocaine self-administration in rats. Brain Res, 722(1-2): 145-152.

Han J, Li Y, Wang D, Wei C, Yang X, Sui N. 2010. Effect of 5-aza-2deoxycytidine microinjecting into hippocampus and prelimbic cortex on acquisition and retrieval of cocaine-induced place preference in C57BL/6 mice. Eur J Pharmacol, 642(1-3): 93-98.

Hyman SE, Malenka RC, Nestler EJ. 2006. Neural mechanisms of addiction: the role of reward-related learning and memory. Annu Rev Neurosci, 29(1): 565-598.

Lai YT, Fan HY, Cherng CG, Chiang CY, Kao GS, Yu L. 2008. Activation of amygdaloid PKC pathway is necessary for conditioned cues-provoked cocaine memory performance. Neurobiol Learn Mem, 90(1): 164-170.

Lee JL, Di Ciano P, Thomas KL, Everitt BJ. 2005. Disrupting reconsolidation of drug memories reduces cocaine-seeking behavior. Neuron, 47(6): 795-801.

Maratos EJ, Dolan RJ, Morris JS, Henson RN, Rugg MD. 2001. Neural activity associated with episodic memory for emotional context. Neuropsychologia, 39(9): 910-920.

Meng Z, Liu C, Hu X, Ma Y. 2009. Somatosensory cortices are required for the acquisition of morphine-induced conditioned place preference. PLoS One, 4: e7742.

Milekic MH, Brown SD, Castellini C, Alberini CM. 2006. Persistent disruption of an established morphine conditioned place preference. $J$ Neurosci, 26(11): 3010-3020.

Mueller D, Stewart J. 2000. Cocaine-induced conditioned place 
preference: reinstatement by priming injections of cocaine after extinction. Behav Brain Res, 115(1): 39-47.

Nader K. 2003. Memory traces unbound. Trends Neurosci, 26(2): 65-72.

Nader K, Schafe GE, Le Doux JE. 2000. Fear memories require protein synthesis in the amygdala for reconsolidation after retrieval. Nature, 406(6797): 722-726.

Nikzad S, Vafaei AA, Rashidy-Pour A, Haghighi S. 2011. Systemic and intrahippocampal administrations of the glucocorticoid receptor antagonist RU38486 impairs fear memory reconsolidation in rats. Stress, 14(4): 459-464.

Pesini P, Detheux M, Parmentier M, Hokfelt T. 1998. Distribution of a glucocorticoid-induced orphan receptor (JP05) mRNA in the central nervous system of the mouse. Brain Res Mol Brain Res, 57(2): 281-300.

Piazza PV, Le Moal M. 1997. Glucocorticoids as a biological substrate of reward: physiological and pathophysiological implications. Brain Res Brain Res Rev, 25(3): 359-372.

Piazza PV, Rouge-Pont F, Deroche V, Maccari S, Simon H, Le Moal M. 1996. Glucocorticoids have state-dependent stimulant effects on the mesencephalic dopaminergic transmission. Proc Natl Acad Sci USA, 93(16): 8716-8720.

Riedel G, Micheau J, Lam AG, Roloff EL, Martin SJ, Bridge H, de Hoz L, Poeschel B, McCulloch J, Morris RG. 1999. Reversible neural inactivation reveals hippocampal participation in several memory processes. Nat Neurosci, 2(10): 898-905.

Robinson TE, Berridge KC. 1993. The neural basis of drug craving: an incentive-sensitization theory of addiction. Brain Res Brain Res Rev, 18(3): 247-291.

Roozendaal B, McEwen BS, Chattarji S. 2009. Stress, memory and the amygdala. Nat Rev Neurosci, 10(6): 423-433.
Shalev U, Grimm JW, Shaham Y. 2002. Neurobiology of relapse to heroin and cocaine seeking: a review. Pharmacol Rev, 54(1): 1-42.

Song M, Wang XY, Zhao M, Zhai HF, Lu L. 2007. Role of stress in acquisition of alcohol-conditioned place preference in adolescent and adult mice. Alcohol Clin Exp Res, 31(12): 2001-2005.

Tan H, Liu N, Wilson FA, Ma Y. 2007. Effects of scopolamine on morphine-induced conditioned place preference in mice. Addict Biol, 12(3-4): 463-469.

Tilley MR, Cagniard B, Zhuang X, Han DD, Tiao N, Gu HH. 2007. Cocaine reward and locomotion stimulation in mice with reduced dopamine transporter expression. BMC Neurosci, 8(1): 42.

Valjent E, Corbille AG, Bertran-Gonzalez J, Herve D, Girault JA. 2006. Inhibition of ERK pathway or protein synthesis during reexposure to drugs of abuse erases previously learned place preference. Proc Natl Acad Sci USA, 103(8): 2932-2937.

Wang J, Fang Q, Liu Z, Lu L. 2006. Region-specific effects of brain corticotropin-releasing factor receptor type 1 blockade on footshockstress-or drug-priming-induced reinstatement of morphine conditioned place preference in rats. Psychopharmacology (Berl), 185(1): 19-28.

Wang XY, Zhao M, Ghitza UE, Li YQ, Lu L. 2008. Stress impairs reconsolidation of drug memory via glucocorticoid receptors in the basolateral amygdala. J Neurosci, 28(21): 5602-5610.

Wolkowitz OM, Burke H, Epel ES, Reus VI. 2009. Glucocorticoids. Mood, memory, and mechanisms. Ann N Y Acad Sci, 1179: 19-40.

Zhai H, Wu P, Chen S, Li F, Liu Y, Lu L. 2008. Effects of scopolamine and ketamine on reconsolidation of morphine conditioned place preference in rats. Behav Pharmacol, 19(3): 211-216.

Zhao X, Li Y, Peng T, Seese RR, Wang Z. 2011. Stress impairs consolidation of recognition memory after blocking drug memory reconsolidation. Neurosci Lett, 501(1): 50-54. 